\title{
New Gas Chromatographic/Mass Spectrometric Method for Ortho-Cresol Detection in Urine
}

\author{
Ane K. S. Frohlich ${ }^{1,2}$, Viviane C. Sebben ${ }^{2}$ and Alexandre B. F. Ferraz ${ }^{1^{*}}$ \\ ${ }^{1}$ Post Graduate Program in Genetics and Applied Toxicology, Lutheran University of Brazil (ULBRA), Canoas, Rio Grande do Sul, Brazil \\ ${ }^{2}$ Nucleus of Analytical Toxicology, Toxicology Information Center of Rio Grande do Sul (CIT/RS), State Foundation in Production and Health Research \\ (FEPPS), Porto Alegre, Rio Grande do Sul, Brazil
}

Received: January 11,2017; Accepted: May 27,2017; Published: June 27,2017

*Corresponding authors: Alexandre B. F. Ferraz, Lutheran University of Brazil (ULBRA), Post Graduate Program in Genetics and Applied Toxicology, Avenida Farroupilha, 8001, Canoas, Zip Code 9242-5900, Rio Grande do Sul, Brazil. Phone: +55 5134779158; E-mail: tcheferraz@gmail.com

\begin{abstract}
The Brazilian Regulatory Norms (NR) establishes safety conditions for workers. However, many analytical parameters are outdated, and toxicological analyses are complemented by international standards. Since toluene is present in the most common footwear activities, workers in this area need an effective biomonitoring method concerning this chemical agent. Ortho-cresol is one of the metabolites from toluene biotransformation, which due to its specificity and selectivity is recommended by the American Conference of Governmental Industrial Hygienists (ACGIH) as a reference biomarker. For detection of ortho-cresol in urine, we proposed an analytical method using gas chromatography-mass spectrometry (GC/MS) with Solid Phase Extraction (SPE). This method was shown to be an efficient laboratorial analysis, able to detect low concentrations of ortho-cresol. SPE has shown better efficiency when compared to SPME, generating a more specific analytical method to detect toluene exposure. This validated bioanalytical method is an assay category II, with specificity and limit of detection parameters in accordance to ANVISA.
\end{abstract}

Keywords: Biomonitoring; Toluene; Ortho-Cresol; GC/MS, SPE

\section{Introduction}

New Gas Chromatographic/Mass Spectrometric Method for Ortho-Cresol Detection in Urine

Brazil is placed as the third country with the highest footwear production. In Rio Grande do Sul, there are more than 3,400 footwear companies, generating 129,700 jobs, mainly at the Valley of Sinos [1]. Daily, these workers are occupationally exposed to toluene, which is the main chemical agent involved in the industrial production of footwear. Due to the toxicological nature of toluene, effective biomonitoring of this compound is necessary to ensure the health of this worker [2].

The Regulatory Norm $\mathrm{N}^{\circ} 7\left(\mathrm{NR}^{\circ} 7\right)$ states that the Medical Control Program of Occupational Health (PCMSO) chooses parameters for the biological control to chemical agent's exposure [3]. Nevertheless, between 2007 and 2012, 1,872 cases of hearing loss were reported, and $24.5 \%$ of these cases were caused by occupational exposure to toluene [4]. For the biomonitoring of this compound, Brazilian legislation recommends hippuric acid analysis in urine. However, despite the fact that hippuric acid is the major metabolite of toluene excreted by the urinary route, the analysis of this biomarker should be reconsidered, since it can also be found as an endogenous agent and its biological concentration has inter individual variety. These statements show that there might be an interference in the concentrations of this compound caused by external conditions, as diets rich in benzoic acid, which is a precursor of hippuric acid, and also by its instability through urinary excretion [5]. Therefore, the use of hippuric acid as a biomarker for toluene exposure is questionable, since orthocresol is currently recommended as a biomarker by the American Conference of Governmental Industrial Hygienists (ACGIH).

The safety Brazilian norms are outdated when compared to values standardized internationally. It can be noted that chemical tolerance limits accepted by other countries are lower than those adopted in Brazil [6]. For toluene biomonitoring, NR $N^{\circ} 7$ establishes hippuric acid in urine as the only biomarker with Biological Exposure Indices (BEI) at $2.5 \mathrm{~g} / \mathrm{g}$ creatinine. For example ACGIH monitors the occupational health by ortho-cresol analysis in urine and toluene in blood and urine, establishing BEI of $0.3 \mathrm{mg} / \mathrm{g}$ creatinine, $0.02 \mathrm{mg} / \mathrm{L}$ and $0.03 \mathrm{mg} / \mathrm{L}$ respectively. Also, Mexican Official Norm No 047 establishes biomarkers for toluene exposure, ortho-cresol and hippuric acid in urine and toluene in blood with BEI of $0.5 \mathrm{mg} / \mathrm{L}, 1.6 \mathrm{~g} / \mathrm{g}$ creatinine e 0.05 $\mathrm{mg} / \mathrm{L}$ respectively $[3,7,8]$.

For biomonitoring analysis, new preparation techniques have been employing with advantages compared to conventional methods, such as reducing the organic solvents consumption, diminished of sample degradation and sample concentration [9]. In this study, Solid Phase Extraction (SPE) and Solid Phase Microextraction (SPME) were used as extraction method for ortho-cresol in urine. SPE is a selective, efficient and cheap method that allows treatment of complex matrixes using smaller volumes of solvents, eliminating emulsion during the extraction process. In the other hand, SPME shares the use of smaller 
amounts of organic solvents and also eliminates contaminants. This process occurs based in the equilibrium of the analyte between the matrix and the polymeric phase in the SPME system $[9,10,11,12]$.

The gas chromatography-mass spectrometry (GC/MS) analysis contributes to greater selectivity, higher separation efficiency, detection of lower concentrations, and also allows the identification of the compounds by their chemical structures. This analytical methodology is well known and largely used for trace analysis of many chemical compounds, which is an analytical advantage when compared to High Performance Liquid Chromatography (HPLC) [13]. Thus, the aim of this study was to develop a biomonitoring methodology for toluene exposure using GC/MS for detection and quantification of ortho-cresol in urine samples.

\section{Material and Methods}

\section{Chemical Reagents}

Ortho-cresol (99\%) standard was purchased from Fluka Sigma Aldrich $®$ (Germany). Ortho-cresol main working solution was prepared in acetonitrile obtained from Merck® (Darmstadt, Germany), to the concentration of $5 \mathrm{mg} / \mathrm{L}$. For the SPME tests, according to Fustinoni et al. [14], sodium chloride and sodium hydroxide were purchased from Vetec $\AA$ (Rio de Janeiro, Brazil), hydrochloric acid; ethyl acetate and acetic acid were obtained from Dinâmica ${ }^{\circledR}$ (São Paulo, Brazil). Sample preparation for SPE required the use of potassium monobasic phosphate, ethyl acetate obtained from Vetec $₫$ (Rio de Janeiro, Brazil), methanol obtained from Synth $®$ (São Paulo, Brazil), acetic acid, hexane and methylene chloride obtained from Dinâmica ${ }^{\circledR}$ (São Paulo, Brazil). SPE cartridges, C18 and Bond Elut Certify, were acquired from Agilent ${ }^{\circledR}$ (Agilent Technologies, Inc., Palo Alto, CA, USA).

\section{Chromatographical conditions: GC/MS}

Chromatographic analysis was performed using an Agilent 7890a gas chromatograph (Agilent Technologies, Inc., Palo Alto, CA, USA) coupled with a 5975C Agilent mass selective detector (MSD) (Agilent Technologies, Inc., Palo Alto, CA, USA). The analytical data were obtained using MSD ChemStation software (version E02.02.1431). Chromatographic separation was achieved on a low bleed capillary GC column (30 m x 0.25 $\mathrm{mm}$ i.d $\times 0.25 \mu \mathrm{m}$ film thickness) with $5 \%$ phenylmethylsiloxane (HP-5 MS), supplied by J \& W Scientific (Folsom, CA, USA).

Analytical conditions were based on Fustinoni et al. [14]: Injection port temperature and transfer line temperature were set to $250^{\circ} \mathrm{C}$. Helium (He) 6.0 (99.9999\%) was used as carrier gas at $1 \mathrm{~mL} / \mathrm{min}$ in constant flow with the injection port operating in splitless mode. Initial oven temperature was set to $60^{\circ} \mathrm{C}$ for $1 \mathrm{~min}$, which was increased by $20^{\circ} \mathrm{C} / \mathrm{min}$ to $80^{\circ} \mathrm{C}$ with a hold of $0.50 \mathrm{~min}$, increased by $10^{\circ} \mathrm{C} / \mathrm{min}$ to $100^{\circ} \mathrm{C}$ for $0.50 \mathrm{~min}$ and finally increased by $50^{\circ} \mathrm{C} / \mathrm{min}$ to $180{ }^{\circ} \mathrm{C}$. Injection volume was set to $1 \mu \mathrm{L}$.

MSD's temperature was set to $280^{\circ} \mathrm{C}$ and it was operated in electronic impact (EI) mode with electronic energy set to $70 \mathrm{eV}$ in Selected Ion Monitoring (SIM) mode with the following ions chosen for identification: 77, 107 e 108.

\section{Sample preparation}

SPME tests were performed according to the conditions presented by Fustinoni et al. [14]. Urine samples, at room temperature, were centrifuged and $0.30 \mathrm{~mL}$ from the supernatants was transferred to headspace tubes $(2 \mathrm{~mL})$ containing $300 \mathrm{mg}$ of $\mathrm{NaCl}$ and $50 \mu \mathrm{L}$ of the aqueous solution of $\mathrm{HCl} 37 \%$. The tubes were sealed and submitted to rigorous agitation, after were placed in a boiling water bath $\left(100^{\circ} \mathrm{C}\right)$ for $60 \mathrm{~min}$. After heating, the tubes were left at room temperature for $15 \mathrm{~min}$ and cooled to $-20^{\circ} \mathrm{C}$ for $90 \mathrm{~min}$. To adjust the $\mathrm{pH}$ of the cooled samples, 50 $\mu \mathrm{L}$ of $\mathrm{NaOH} 10 \mathrm{~mol}^{-1} \mathrm{~L}^{-1}$ and $300 \mu \mathrm{L}$ of 1 mol.L $\mathrm{L}^{-1}$ ethyl acetate/acetic acid buffer were added. The tube was heated at $150^{\circ} \mathrm{C}$ and stirred in a magnetic stirrer with a hot plate for $30 \mathrm{~min}$. The SPME fiber was exposed to the headspace for $30 \mathrm{~min}$ and then injected in the injection port.

SPE was performed using Bond Elut Certify cartridges from Agilent ${ }^{\circledR}$ (Agilent Technologies, Inc., Palo Alto, CA, USA). The cartridge was preconditioned with $2.0 \mathrm{~mL}$ of methanol and subsequently with $2.0 \mathrm{~mL}$ of phosphate buffer $0.1 \mathrm{M}(\mathrm{pH} 6.0)$. Urine samples fortified with working solutions of ortho-cresol working solutions at many concentrations were transferred to the cartridge $5 \mathrm{~mL}$ of fortified urine and $2 \mathrm{~mL}$ of phosphate buffer 0.1 mol. $\mathrm{L}^{-1} \mathrm{pH} 6$ were mixed and stirred. $\mathrm{pH}$ was adjusted between 5 and 7), which was then washed with $1 \mathrm{~mL}$ of phosphate buffer pH 6/ methanol (80:20) and vacuumed for 2 min, washed again with $1 \mathrm{~mL}$ of acetic acid $1 \mathrm{~mol} . \mathrm{L}^{-1}$, vacuumed for $10 \mathrm{~min}$., washed with $1 \mathrm{~mL}$ of hexane and vacuumed for $2 \mathrm{~min}$. Analytes' elution was performed with $4 \mathrm{~mL}$ of methylene chloride. The eluent was evaporated to dryness under a fine stream of nitrogen at $60^{\circ} \mathrm{C}$. To the dried extract, $100 \mu \mathrm{L}$ of ethyl acetate were added. Aliquots (1 $\mu \mathrm{L}$ ) were injected in the GC/MS.

\section{Results and Discussions}

All tests for ortho-cresol analysis in urine by GC/MS by SPME following the conditions established by Fustinoni et al. [14]. This extraction method required an initial acid hydrolysis to rupture the between ortho-cresol and glucuronic acid bond. Then, hydrolyzed sample was frozen, in order to avoid the ortho-cresol volatility and loss. This study optimized the method developed by Fustinoni et al. [14] by using a DB-5 column instead of a DBwax. This exchange had to be performed, since in this study the concentration described for ortho-cresol $(0.006 \mathrm{mg} / \mathrm{L})$ was not detectable by DB-wax column [14].

The polydimethylsiloxane (PDMS) fiber was used for SPME system in a headspace mode. The lack of technical efficiency for detection in lower concentrations may be explained by the fiber coating. The lack of technical efficiency for detection in lower concentrations may be explained by the fiber coating. Once, that exist a higher affinity between cresols and carbowaxdivinylbenzene (CW-DVB), reaching 100\%, while PDMS fibers have an affinity of 38\% Fustinoni et al. [14]. Netto et al. [15], in their experience with urinary toluene, showed better SPME 
results using a carboxen-PDMS coated fiber, since the PDMS fiber is not recommended for mild exposures to toluene, like the results presented by this study $[14,15]$.

The difficulties working in low concentrations with SPME may be related to the extraction process, which is based among three phases: extraction fiber, vapor phase and the matrix in which mass transfer occurs. The efficiency of SPME depends on the concentration of vapor phase, the fiber adsorption capacity and desorption capacity at injection port temperature. The analyte will be extracted until it reaches the equilibrium, determined by the activity coefficient at infinite dilution of pure solvents [16].

The quantification method for Ortho-cresol detection in urine using SPE showed great results. This procedure allowed the quantification and identification of this compound at $0.06 \mathrm{mg} / \mathrm{L}$ (Figure 1). The methylene chloride was added for ortho-cresol elution and hexane to remove contaminants. These solvents were previously used to clean up samples with saturated hydrocarbons, polycyclic aromatics and alquiphenols $[17,18]$.
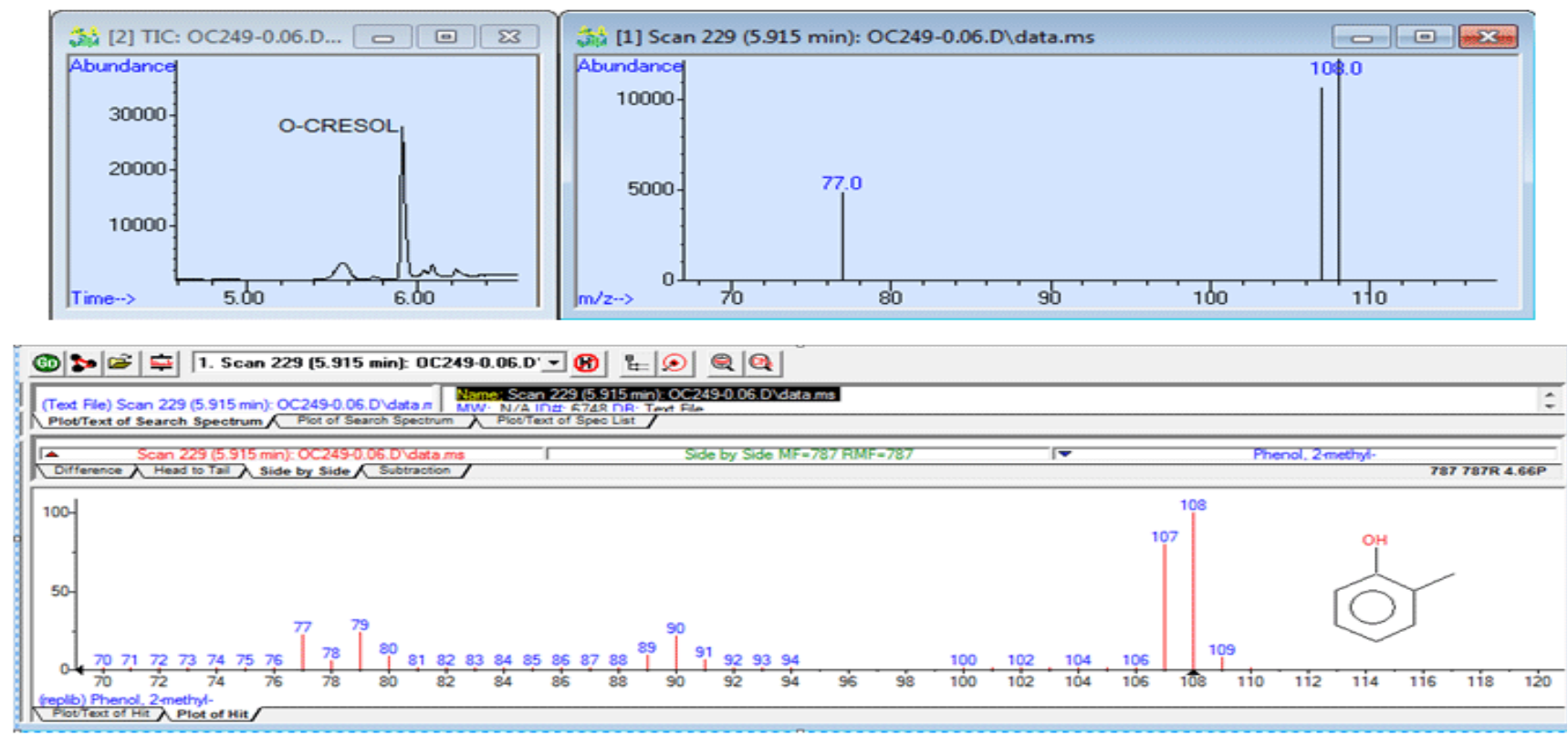

Figure 1: Chromatogram of a urine sample using SPE and the respective mass spectrum of ortho-cresol (Retention Time: 5.915 min)

For the SPE method, two different cartridges were tested C18 (nonpolar) and Bond Elut Certify (cationic). After the ortho-cresol extraction from urine sample at the concentration of $5 \mathrm{mg} / \mathrm{L}$ in acid $\mathrm{pH}$, the cationic cartridge proved to be more efficient reaching almost $100 \%$ when compared to the C18 cartridge, Figure 2. These results agree with obtained data by Daszkiewicz et al. [19] that described a $6 \%$ recovery for phenolic compounds using C18 and a recovery close to $100 \%$ using SPE cartridges made by sorbents based on modified resins [19].

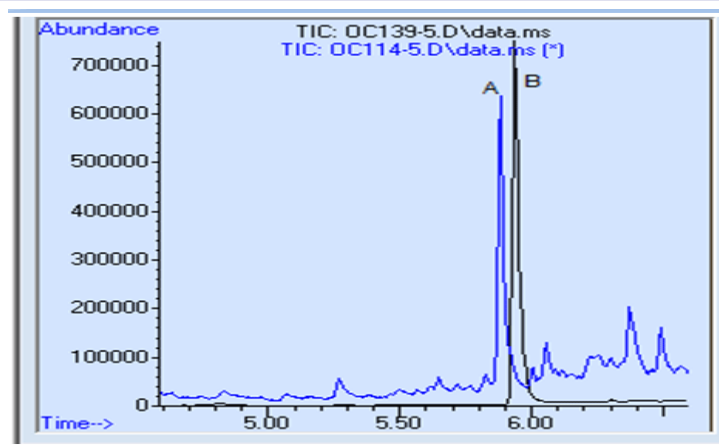

Figure 2: Chromatograms of the same sample extracted with different SPE cartridges. A: C18 and B: Bond Elut Certify
The method developed using SPE have showed robustness, therefore the times elapsed in each step of the extraction described earlier, were precisely reproduced at each new analysis. The standard solutions were kept away from natural light, to avoid the degradation of ortho-cresol, at the temperature of $-20^{\circ} \mathrm{C}$, during six months, according to Fustinoni et al. [14]. The autosampler presented low stability, requering agile injection in gas chromatograph. Also to keep a high robustness, the analytical parameters of temperature and velocity of the carrier gas were tested and established. During the optimization of chromatographic period there was any change in the chromatographic column keeping the same lot and fabricant $[14,20]$.

Specificity is the parameter recommended for the evaluation of the degree of interference in the detection of the selected substance. This can be obtained comparing by massspectrometry the spectrum of matrix and sample containing the analyte with the analysis of peak standard [21]. Both procedures were contemplated by the analysis of matrix and sample with ortho-cresol at the mass-spectrometer library (Figure 1) [22,23].

For the linearity analysis, different concentrations of ortho-cresol standard were used to obtain the calibration curve 
$(\mathrm{R}>0.98)$, in agreement with National Health Surveillance Agency (ANVISA). The value of $0.3 \mathrm{mg} / \mathrm{g}$ creatinine was used as a reference for the exposure to toluene. This is the BEI value indicated by ACGIH. The division of creatinine reference value $(0.4$ - $3.5 \mathrm{~g} / \mathrm{L}$ ) by BEI provided the lowest and highest values of urinary creatinine $(0.086-0.75 \mathrm{mg} / \mathrm{L})$. Based on this concentration range a calibration curve $(0.06 ; 0.12 ; 0.25 ; 0.5 ; 1.0$ e $4.0 \mathrm{mg} / \mathrm{L})$ for the guidance of the clinical exposure was obtained with $\mathrm{R}=$ 0.99. According to this curve, it was possible to find points with regular tendency, ensuring linearity and demonstrating strong correlation $[20,24]$ The linearity obtained in this study is the same obtained by Fustinoni et al. [14], for the calibration curve of de ortho-cresol.

Following the requirements of ACGIH for ortho-cresol BEI $(0.3 \mathrm{mg} / \mathrm{g}$ creatinine), it was possible to develop an analytical method able to detect ortho-cresol at lower concentrations using gas chromatography coupled with mass spectrometry. Also was showed that GC/MS has higher efficiency to detected orthocresol than high performance liquid chromatography [13]. This advantage in the ortho-cresol analysis can be observed by the limit of detection at trace levels $(0.025 \mathrm{mg} / \mathrm{L})$ showed in Figure 3 and the limit of quantification $(0.06 \mathrm{mg} / \mathrm{L})$ (Figure 4).

In addition, this method to detected ortho-cresol at lower concentrations when compared to the limit of detection of $0.03 \mathrm{mg} / \mathrm{L}$ and quantification of $0.09 \mathrm{mg} / \mathrm{L}$ found by Vrsaljko et al. [13]. The limit of quantification is another important quantitative aspect for detection and quantification os substances. The present method showed accuracy and precision of values (116 $\%$ and $12 \%$ respectively) in accordance with recommended by Anvisa (Table 1) [7,20].

Additionally, we evaluated by this method a urine sample positive for hipuric acid ( $3.0 \mathrm{~g} / \mathrm{g}$ creatinine). Although, we found difficult to quantify ortho-cresol because the chromatographic peak amplitude is smaller than our limit of the quantification on the calibration curve (Figure 5).

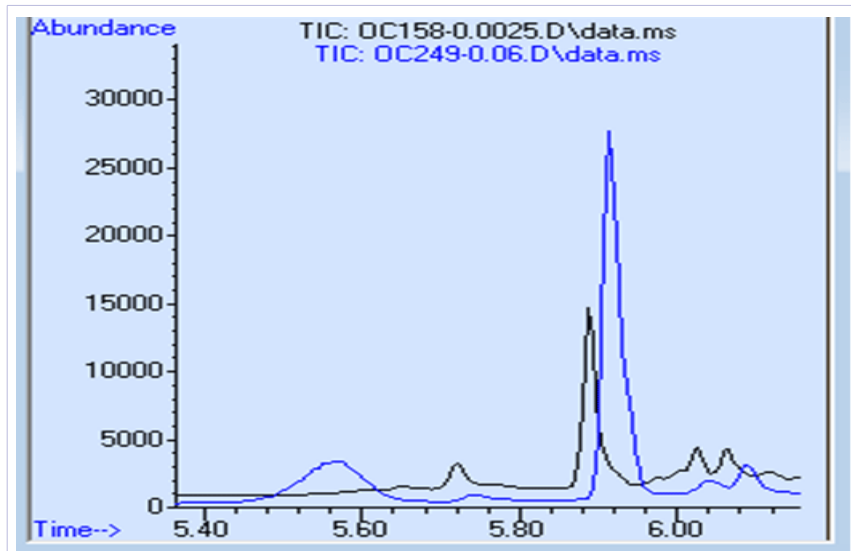

Figure 3: Chromatogram of the limit of detection $(0.0025 \mathrm{mg} / \mathrm{L}) \mathrm{com}-$ pared of the limit of quantification for ortho-cresol

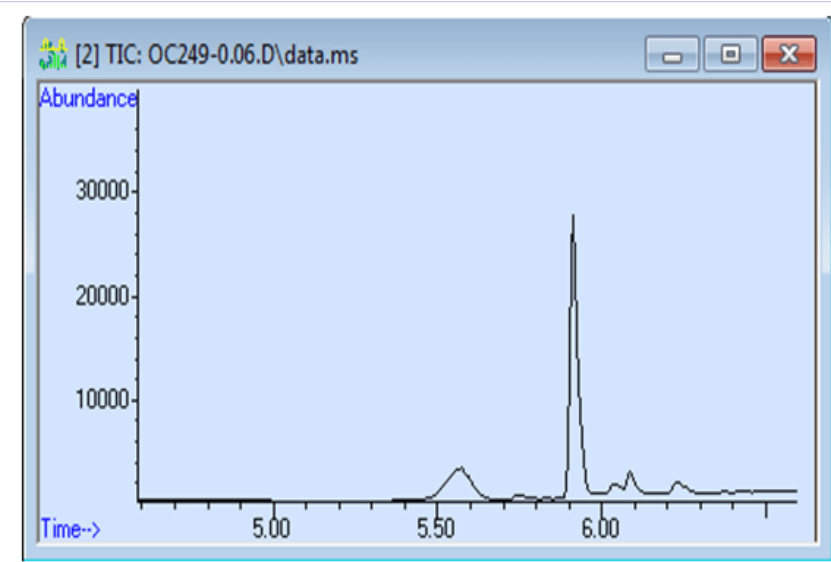

Figure 4: Chromatogram of the limit of quantification $(0.06 \mathrm{mg} / \mathrm{L})$ for ortho-cresol

Table 1: Parameters for validation method by Anvisa

\begin{tabular}{|l|l|l|}
\hline Parameters & Reference Anvisa & Analyzes \\
\hline Linearity & 0.98 & 0.99 \\
\hline Lower level of detection & Lower level of detection & $0.025 \mathrm{mg} / \mathrm{L}$ \\
\hline Lower level of quantitation & Lower level of quantitation & $0.06 \mathrm{mg} / \mathrm{L}$ \\
& Precision $20 \%$ & Precision $12 \%$ \\
& Accuracy $80-120 \%$ & Accuracy $116 \%$ \\
\hline Stability standard solutions & check & Six months \\
\hline Standard purity & check & $99.9 \%$ \\
\hline
\end{tabular}



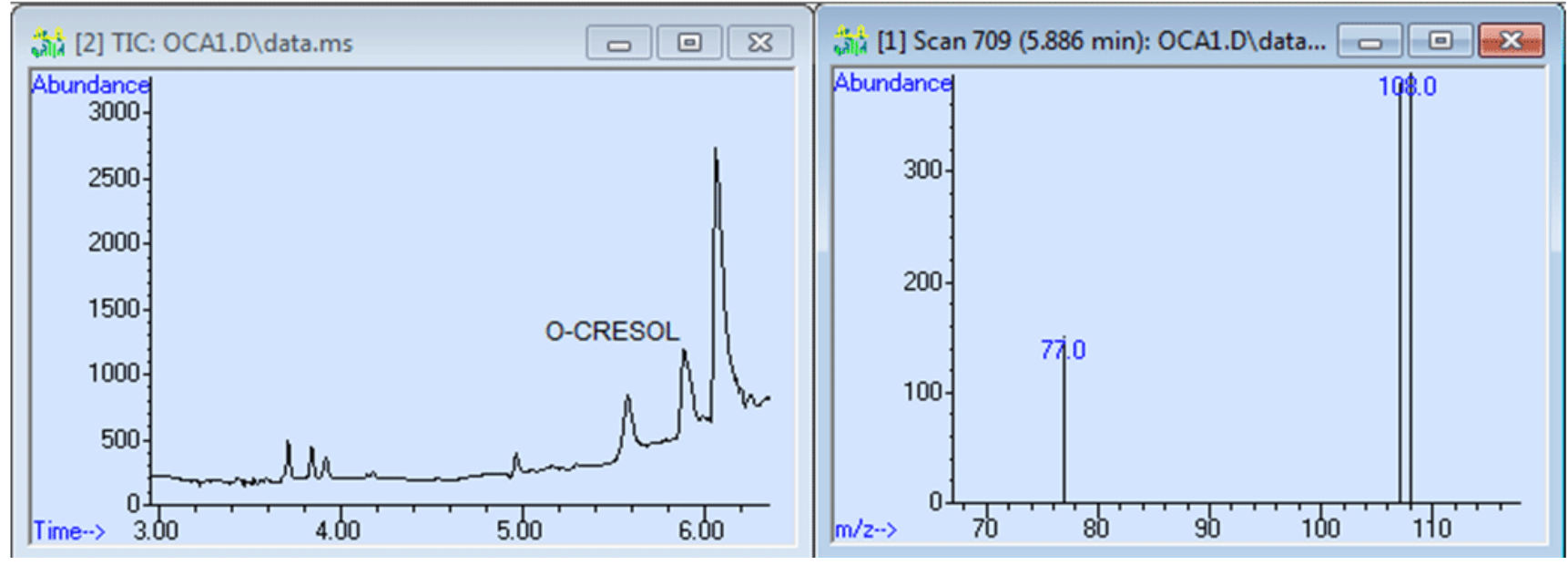

Figure 5: Chromatogram of the urine sample

\section{Conclusions}

The developed method for ortho-cresol detection by SPE indicated to be more effective than the other using SPME. For the SPE extraction a cationic cartridge is recommended (e.g. Bond Elut Certify) due to employment of acid extraction. This validated bioanalytical method is an assay category II, with specificity, robustness and limit of detection parameters in accordance to Anvisa.

Therefore, the developed method for ortho-cresol in urine using SPE extraction and detection by GC/MS offer a new a routine for toluene biomonitoring in toxicology laboratory. This technics allow the detection and quantification of ortho- cresol in milder exposures to toluene, considering the BEI recommended by the ACGIH.

\section{Acknowledgments}

The authors would like to thank the Toxicology Information Center of Rio Grande do Sul (CIT/RS) and Post Graduate Program in Genetics and Applied Toxicology (PPGGTA/ULBRA).

\section{References}

1. Brazilian Association of Footwear Industries. Annual report 2009. Access in: February 2015.

2. Ancines C. Biomonitoring in workers of the leather-footwear sector of Rio Grande do Sul. Graduation Conclusion Paper, Federal University of Rio Grande do Sul, Brazil, 2011.

3. Brasil. Regulatary Norm n 7, 1994. Access in: January 2015.

4. Oliveira CH, Haddad MCL, Rossaines MA, Scaramal DA. Hearing loss induced by noise in servers of a Public State University. Cogitare Enferm. 2015; 20(1): 96-102.

5. Gonzalez KC, Sagebin FR, Oliveira PG, Glock L, Thiesen FV. Retrospective study of urinary hippuric acid levels in occupational toxicology tests. Ciência e Saúde Coletiva. 2010;15(1): 1637-1641.

6. Rocha JR, Quelhas OLG, Gomes RS. Critical analysis of Brazilian occu- pational health and safety legislation. The case of exposure to chemical agents. Summary of the VII National Congress of Excellence in Management, Rio de Janeiro, Brazil, 2011.

7. American Conference of Governamental Industrial Hygienists - ACGIH, Threshold Limit Values for chemical substances and physical agents e biological exposure indices, USA, 2011.

8. Norma Oficial Mexicana, Salud ambiental-Indices biológicos de exposición para el personal ocupacionalmente expuesto a sustancias químicas, Mexico, 2011. Access in: April 2015.

9. Li J, Wang YB, Li KY, Cao YQ Wu S, Wu L. Advances in different configurations of solid-phase microextraction and their applications in food and environmental analysis. Trends Anal. Chem. 2015;74:141-152. DOI: $10.1016 /$ j.trac.2015.04.023

10.Jardim ICSF. Solid Phase Extraction: Theoretical Basics and New Strategies for Solid Phase Preparation. Scientia Cromatographyca. 2010;2(1):13-25.

11. Menezes HC, Cardeal ZL. Development of a new solid phase microextraction system with cooled fiber. Scientia Chromatographica. 2013;5(4):301-309.

12. Daszkiewicz KB, Voelkel A. Theoretical and experimental methods of determination of the breakthrough volume of SPE sorbents. Talanta. 2009;80(2):614-621. doi: 10.1016/j.talanta.2009.07.037

13.Vrsaljko D, Haramija V, Hadzi-Skerlev A. Determination of phenol, m-cresol and o-cresol in transformer oil by HPLC method. Electr. Power Syst. Res. 2012;93:24-31. doi:10.1016/j.epsr.2012.07.006. doi:10.1016/j.epsr.2012.07.006.

14. Fustinoni S, Mercadante R, Campo L, Scibetta L, Valla C, Foá V. Determination of urinary ortho- and meta-cresol in humans by headspace SPME gas chromatography/mass spectrometry. J. Chromatogr. B: Anal. Technol. Biomed. Life Sci. 2005;817(2):309-317. doi: 10.1016/j. jchromb.2004.12.029

15. Netto DC, Reis RM, Mendes CB, Gomes PCFL, Martins I, Siqueira MEPB. 
Headspace solid-phase microextraction procedure for gas-chromatography analysis of toluene in urine J. Braz. Chem. Soc. 2008;19(6):12011206.

16. Fonseca DB, Coelho GLV. Determination of the activity coefficient in infinite dilution $(\gamma \infty)$ through micro-extraction in solid phase (SPME). Quim. Nova. 2007;30(7):1606-1608.

17. Rebouças LMC, Nogueira FAR, Sabino AR, Morais RJR, Sant'Ana AEG. Summary of the 40th Brazilian Congress on Oil and Gas R \& D (PDPETRO), Campinas, Brazil, 2007.

18. Rebouças LMC, Nogueira FAR, Sabino AR, Morais RJR, Sant'Ana AEG. Saturated and aromatic polycyclic hydrocarbons in oils of the pilar field, alagoas sub-basin: identification and concentration. Geochim. Brasiliensis. 2008;22(2):91-102.

19. Daszkiewicz KB, Voelkel A, Szeejner M, Osypiuk J. Optimization of SPE/GC/HPLC Analytical Procedure for Determination of Phenol, Quinones, and Carboxylic Acids in Water Samples. ISRN Chromatogr.
2012. doi: $10.5402 / 2012 / 680929$.

20. Brasil. Resolução n. 899, 29 de maio de 2003. Access in: April 2015.

21. Ribani M, Bottoli CBG, Collins CH, Jardim ICSF, Melo LFC. Validation for chromatographic and electrophoretic methods. Quim Nova. 2004;27(5):771-780. doi: 10.1590/S0100-40422004000500017

22. Fonseca EP, Johann I, Alegretti A, Thiesen FV. Chimarrão consumption interference and hippuric acid urine levels. Rev. Bras. Anal Clin. 2006;38(3):163-165.

23. Bulcão R, Maria LS, Charão M, Moro A, Roehrs M, Garcia SC. Simultaneous quantification of biological indicators for solvent exposure organic by high efficiency liquid chromatography. Quim Nova. 2008;31(6):1343-1348

24. Cassiano NM, Barreiro JC, Martins LRR, Oliveira RV, Cass QB. Validation in chromatographic methods for analysis of small molecules in Biological matrices. Quim Nova. 2009;32(4): 1021-1030. 